\title{
Seasonal laminae in marine sediments: applications and potential
}

\author{
Alan E.S. Kemp
}

\section{Laminated marine sediments have the potential for seasonal resolution that can be exploited using scanning electron microscope techniques. This article provides examples of the power of such an approach.}

\begin{abstract}
Marine varved and laminated sediments are widely distributed (Kemp 2003). They are not restricted to oxygen-depleted marginal basins with shallow sill depths or to productive shelves and slopes, but are increasingly being found in the deep sea where massive particle flux has suppressed benthic activity, preserving seasonal flux events as sedimentary laminae (Kemp et al. 2006). Scanning Electron Microscope (SEM) methods using back-scattered electron imagery (BSEl) have enabled the identification and sub-sampling of near-monospecific diatom laminae from seasonal blooms and flux events. BSEl, when combined with ecological insights, allows the development of a species-based seasonal approach for climate reconstruction in the marine realm. Highlighted here are new methodologies that have increased the resolution of stable isotope proxy applications to a seasonal scale, and also other integrative studies that have provided insights into interannual climate variability and to the biogeochemical carbon cycle.
\end{abstract}

\section{Diatom stable isotope records}

Quantitative paleoceanographic reconstructions of temperature, salinity and ice volume from marine sediments have traditionally used oxygen and carbon isotope analysis of calcite foraminifera shells. However, the resolution of such records is typically centennial at best due to low sedimention rates or low foraminifera abundance in rapidly accumulating sediments. To overcome this limitation and increase the resolution of paleoceanographic research, isotope records are derived from the frustules of diatoms (De La Rocha 2006; Swann and Leng 2009). Near-monospecific diatom blooms can form laminas from millimeters to centimeters in thickness (Fig. 1). The challenge has been to avoid seasonality, habitat, and inter-species effects by isolating diatom samples from a single taxon that grows in a known season and, typically, at known depths in the water column.

The potential for such seasonal-scale isotope proxy resolution is shown by new analyses of sediments from the West Antarctic Peninsula (Swann et al. 2013). In this pioneering study, a micro-manipulator technique has been developed that permits the separation of diatom species for oxygen isotope analysis (Snelling et al. 2013). Two separate species groups were identified as dominant in the laminae: (i) the near-monospecific Hyalochaete Chaetoceros spp. resting spores (CRS) represent spring

\begin{abstract}
deposition linked to sea-ice melt; and (ii) the Thalassiosira antarctica resting spores relate to summer deposition. Oxygen isotope analysis of these two species groups, together with coarse and fine diatom fractions from the same samples, have been used to develop records of changes in magnitude of spring melting and changes in the relative importance of spring sea-ice versus summer glacial-ice melting (Fig. 1). These results offer insights into glacial dynamics and ocean-atmosphere variability on seasonally resolved timescales and, more broadly, point to a future treasure trove of archives for quantitative seasonal palaeoclimatic information.
\end{abstract}

\section{Permanent EI Niño hypothesis}

It has been suggested that the present climate may be approaching a threshold or tipping point that may move the Pacific equatorial ocean-atmosphere system into a permanent El Niño state, with far-reaching implications for global climate (Fedorov and Philander 2000; Fedorov et al. 2006). Supporting evidence has come from foraminiferal paleotemperature studies at multi-millennial resolution suggesting that such a permanent El Niño state existed during the Pliocene warm period



Figure 1: (A) Back-scattered electron imagery (BSEI) photomosaic of a polished thin section (PTS) of resin-embedded seasonally laminated sediments of deglacial age from Palmer Deep, West Antarctic Peninsula. The core interval shows three seasonal flux laminae: (i) spring diatom lamina dominated by Hyalochaete Chaetoceros spp. resting spores (CRS); (ii) summer terrigenous lamina; and (iii) late summer lamina characterized by high abundances of Thalassiosira antarctica resting spores. (B) BSEI of PTS and (C) topographic SEM images of $T$. antarctica resting spore lamina (iii). (D) BSEl and (E) topographic SEM images of CRS lamina (i). (F) Seasonal offset between $\delta^{18} \mathrm{O}_{\text {diatom }}$ for $C R S$ (spring) and T. antarctica RS (summer) sampled from the same year (modified from Maddison 2006 and Swann et al. 2013). 
A

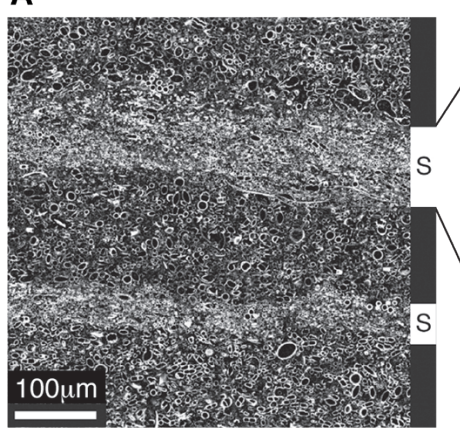

B

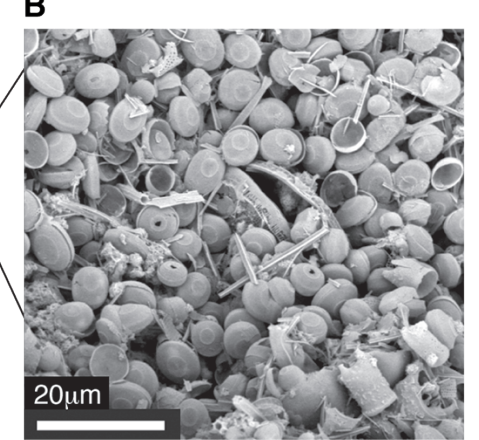

C

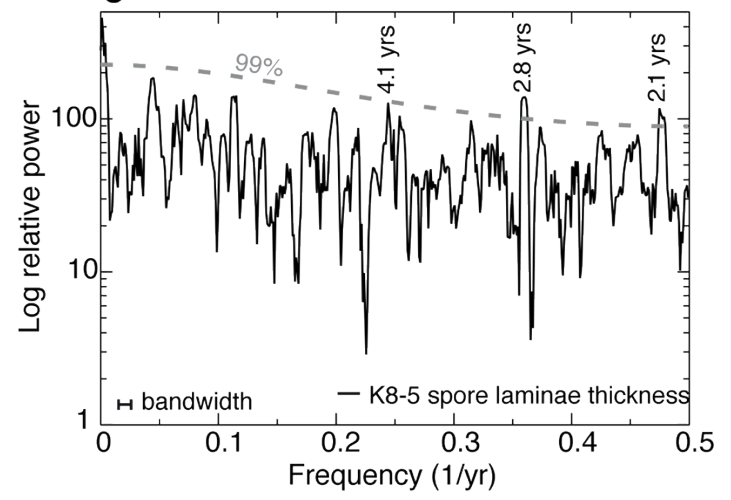

Lamina

Hemiaulusspp. lamina (Summer)

$\mathrm{S}$ Resting spore lamina (Spring)

\section{NINO3 SST} wavelet power spectrum

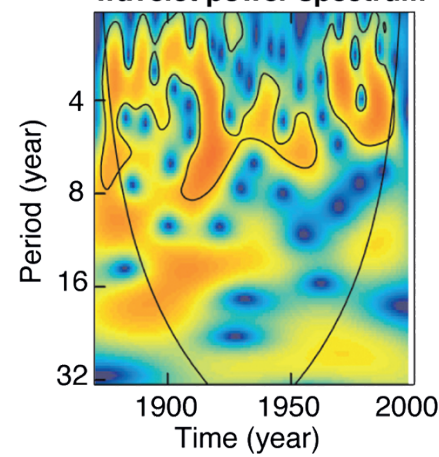

E

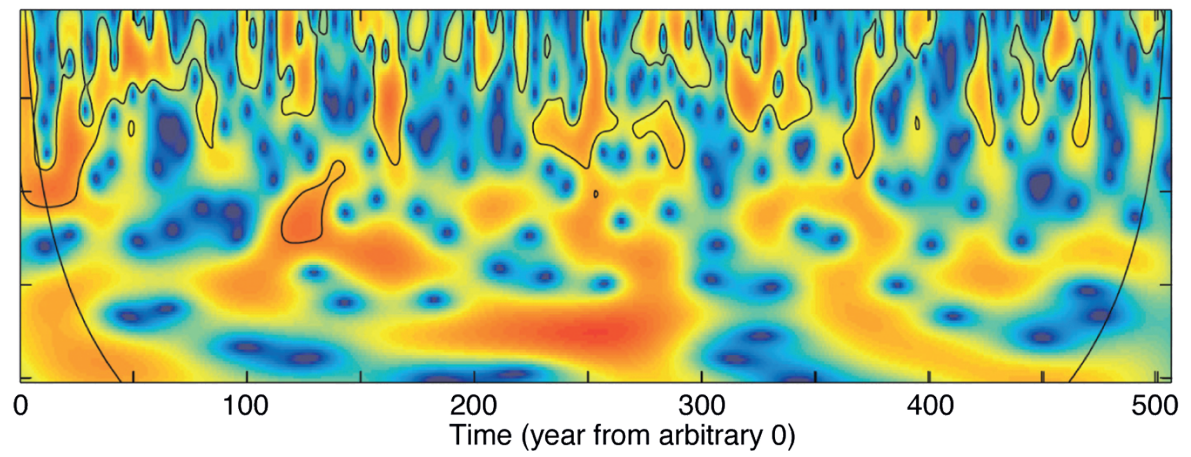

Figure 2: (A) Back-scattered electron imagery (BSEI) of seasonally laminated sediments of Cretaceous age from the Alpha Ridge of the Arctic Ocean. (B) Topographic SEM image of spring Chaetoceros-type resting spore lamina. (C) Multi-taper method (MTM) power spectra of time series of resting spore lamina thickness from a 507-year interval showing peaks significant at 99\% confidence level in the quasi-biennial and typical ENSO low frequency band (4.1 years). (D) and (E) Wavelet power spectra (D) of the Niño3 SST index from 1871 to 1998 (Torrence and Compo 1998) resampled to annual resolution to mimic laminated data, and (E) a 507-year Alpha Ridge record from the late Cretaceous. Late Cretaceous periodicities in the ENSO-band (broadly, 2-8 years) are non-stationary, that is to say, the dominant frequencies vary with time, and show a striking resemblance to similar behavior in the modern ENSO time series. (Adapted from Figs 2-4 of Davies et al. 2011).

(Wara et al. 2005). However, new records from laminated sediments and other seasonally resolved archives from ancient greenhouse periods contradict this hypothesis. Corals from the Pliocene (Watanabe et al. 2011), bivalves from the Eocene (Ivany et al. 2011), annual lamina thicknesses from late Miocene evaporites (Galeotti et al. 2010) and Eocene oil shales (Huber and Caballero 2003; Lenz et al. 2010) have all produced robust El Niño signals during warm periods. The application of BSEI to identify sub-annual lamina components has also contributed to this debate. Further evidence comes from the Cretaceous greenhouse period from California, where time series of alternating seasonal diatom and terrigenous sediment laminae record a strong influence of the El Niño-Southern Oscillation (ENSO) on marine productivity, terrestrial rainfall and run-off (Davies et al. 2012). Exceptionally-preserved Cretaceous-age laminated diatomites from the Arctic Ocean that reveal alternating laminae of spring diatom resting spores and late summer and fall vegetative cells (Davies et al. 2009) have been analyzed to produce a thousand-year time series (Davies et al. 2011). Strong cycles in both the quasi-biennial and the 4-5 year ENSO low frequency band indicate robust El Niño teleconnections to high latitude climate, as occurs today (Fig. 2). This extensive, and increasing, evidence from laminated sediments and other seasonally-resolved archives for a continuously dynamic ENSO even during warm periods does not support the permanent El Niño hypothesis.

\section{Marine biological carbon pump}

One of the long-standing priorities in oceanographic research is to better understand the workings of the biological carbon pump that draws down $\mathrm{CO}_{2}$ from the atmosphere and exports it to the ocean depths. A widespread view has been that increased warming-induced stratification of the oceans will lead to a shift from diatom production to smaller phytoplankton, reducing the effectiveness of the biological pump and acting as a positive feedback that promotes the build up of atmospheric $\mathrm{CO}_{2}$ concentrations and warming of the atmosphere (Steinacher et al. 2010). However, our current understanding of the biological carbon pump is poor. Many of the algal production events that dominate carbon export are spatially and temporally highly restricted, and subsurface processes are not well captured by the conventional oceanographic observations that are biased towards the surface, typically the topmost 20 m (McGillicuddy et al. 2007; Lomas et al. 2009). Sediment traps have been used to record flux from the surface ocean but their positions are localized and they only represent, on aggregate, a record of a few centuries. In contrast, over the past $\sim 20$ years studies of laminated marine sediments have generated many thousands of years of seasonally resolved time series of sediment deposition in widely distributed locations, covering periods from the Cretaceous to the Holocene.

There has recently been a convergence between new oceanographic observations of diatoms in stratified seas and studies of the same taxa in laminated deep-sea sediments. These show that key large-diatom species may bloom and concentrate in stratified surface waters and generate massive carbon flux exceeding that of the spring bloom. Thus, in opposition to the previously favored ideas, stratified oceans may actually enhance carbon export, drawing down $\mathrm{CO}_{2}$ and providing negative feedback to global warming (Kemp and Villareal 2013).

\section{AFFILIATION}

National Oceanography Centre, University of Southampton, UK

\section{CONTACT}

Alan E.S. Kemp: aesk@noc.soton.ac.uk

\section{REFERENCES}

\section{Davies A et al. (2011) Geophys Res Lett 38, doi:}

$$
\text { 03710.01029/02010GL046151 }
$$

Kemp AES (2003) Phil Trans Roy Soc Math Phys Eng Sci 361: 1851-1870

Kemp AES, Villareal TA (2013) Prog Oceanogr 119: 4-23 Snelling AM et al. (2013) Silicon 5: 13-17

Swann GEA et al. (2013) Earth Planet Sci Lett 364: 12-23 